\title{
Assessment of the Performance of Mergers: Revisiting Results after a Prolonged Period
}

\author{
Jan Peta ${ }^{1, *}$, and Maria Reznakova ${ }^{1}$ \\ ${ }^{1}$ Brno University of Technology, Faculty of Business and Management, Department of Finance, \\ Kolejni 4, 61200 Brno, Czech Republic
}

\begin{abstract}
Research background: Mergers and acquisitions (M\&As) have become a widespread tool for business growth strategy. Considering the developments after the previous financial crisis, a fresh wave of M\&As is expected to appear in the near future. Investors will look for suitable businesses to consolidate their market position.

Purpose of the article: The aim of this work is to assess the performance of completed mergers over a period of five years and compare the results with previous research in which we examined the success of mergers over a threeyear period. Our goal was to find out if any differences in performance indicators occur and if these differences are significant. The results may offer potential indicators of merger success rate prediction.

Methods: We focused our research on mergers of private companies (i.e. not publicly traded companies) in the Czech Republic. Our research sample contained 50 completed mergers. The mergers were divided into two groups - successful and unsuccessful - according to the sales and profit of the merged company. We calculated financial indicators for each group based on accounting data. We then used the Mann-Whitney $U$ test to test the significance of the differences between the indicator values.

Findings \& value added: Several important performance indicators emerged. The most significant included production consumption to sales, the material cost to sales, receivables to sales, assets turnover and profitability ratios. The ratio labour cost to sales was replaced with the ratio value added to labour cost. Our research concludes that these indicators can be considered crucial.
\end{abstract}

Keywords: merger and acquisition; predictors; effectiveness; Czech Republic

JEL Classification: $G 34 ; L 25$

\footnotetext{
*Corresponding author: peta@fbm.vutbr.cz
} 


\section{Introduction}

The results of implemented M\&As show that mergers are not always able to achieve their desired goal, which is to create synergies. Merger success evaluation has been the subject of many studies in the past, and some of them even go as far as asserting that there are no combination-related synergies. Martynova and Renneboog [1] analysed studies dealing with M\&As and found that 14 of 26 studies identified a decline in the value of the combined company. Gugler et al. [2] examined 1,250 M\&As completed from 1981 to 1998 and reported a $14.5 \%$ decrease in sales on average in the combined companies compared to the sum of the sales of the original stand-alone companies. Cartwright and Schoenberg [3] found that only $35-45 \%$ of transactions achieved revenue growth two to three years after the merger.

There are several approaches to the assessment of whether an M\&A has been successful or not. One of them, which was also used in our research, is evaluation based on the development of financial indicators. In our research, we focused on the identification of indicators that are most suitable for evaluating the effectiveness of M\&As, as well as on the analysis of the influence of the length of the period on the evaluation of M\&A effectiveness. The motivation for our research is the fact that evaluation of merger effectiveness differs also with regard to when the evaluation takes place, i.e. how many years have passed since the M\&A transaction was completed.

Financial ratios have been used for M\&A effectiveness evaluation by many authors. The question is which indicators are the most suitable for the purpose. Healy et al. [4] assumed an improvement in cash flow after the M\&A. The indicators they used in their research included the operating margin (EBIT/Sales), asset turnover (Sales/Assets) and employee growth rate (change in the number of employees as a percentage of the number of employees in the previous year). Their assumption was confirmed, although the values of the indicators used decreased. However, the decrease was slighter than in companies that did not implement an M\&A. Sorensen [5] also used financial ratios to assess merger success. He found a significant difference in the values of some of the indicators between the companies involved in an M\&A and those that were not. The differences were particularly in profitability ratios (ROS, ROA, ROE) and cash-flow derived ratios, namely $\mathrm{CF} /$ assets and $\mathrm{CF} /$ interest. Significant differences in ROA and ROE ratios have also been confirmed by Shim [6]. Koller et al. [7] recommend evaluation of completed deals from the point of view of sales efficiency, which, according to them, should be reflected in sales growth due to an increased market share. They also assumed a reduction in unit costs due to optimized utilization of resources (a form of economies of scale). The third area in which there should be an improvement thanks to the merger is the efficiency of the invested capital, i.e. return on invested capital. Huyghebaert and Luypaert [8] focused on the analysis of the how mergers are funded. With this purpose in mind, they examined the change in the bank loans to total assets ratio. They found that the share of bank loans in total assets was $23.3 \%$ in companies that had implemented an M\&A, and $24.2 \%$ in other companies. This indicates that the companies did not use debt financing for M\&As as the authors originally assumed.

When evaluating merger effectiveness, Sedláček et al. [9] focused also on the development of financial indicators, namely total assets, operating margin, retained earnings of previous years, labour cost, etc. They assessed the investment effect one to three years after the merger. They found no increase in total assets during the period under consideration but did find an increase in retained earnings and operating margin, as well as in labour cost. It can therefore be assumed that the companies sold part of their assets after the merger or reduced their investments. They apparently also focused on the efficiency of internal processes, which could have resulted in increased profitability. Golubov and Xiong [10] compared the effectiveness of M\&As between public and private companies. In private M\&As, the authors found an average ROA improvement of $7.96 \%$ in the first post-merger 
year and $6.92 \%$ in the third post-merger year. In the case of public M\&As, ROA dropped by $0.77 \%$ in the first year and by as much as $2.07 \%$ in the third post-merger year. A similar development was observed in the return on sales (ROS) indicator. The return on assets ratio in private M\&As increased by an average of $3.48 \%$ in the first year and by $5.14 \%$ in the third year compared to the pre-merger values. In public M\&As, the same indicator deteriorated by $1.61 \%$ and $2.29 \%$, respectively. The ROA indicator development after an M\&A was compared with the situation one year before the deal in a study by Cui and Leung [11], who first found an improvement in the third year after the deal was closed $(0.7 \%)$. They also examined the development of the cash flow from operations indicator, which showed a slight deterioration in all three years reviewed (maximum drop of $0.4 \%$ ). Wu et al. [12] analysed M\&A effectiveness in China using the ROS indicator. They found that the sales median decreased by $8.8 \%$ in the first post-merger year and by even $20.2 \%$ in the following year. The decrease in ROS was, however, observed only in some of the companies examined. If the merger involved a private company, its ROS increased by $20 \%$ over the period under consideration. Also interesting is their observation regarding the size of the merging companies: the authors claim that it is better to buy a smaller company because it is easier to carry out its reorganization.

\subsection{The focus of our research}

The cited research papers come from different periods of M\&A effectiveness evaluation through different types of indicators. The conducted analysis shows that the same transaction can be assessed differently depending on the indicators used. These facts lead to justified doubts about M\&A effectiveness.

Most of the previous research was based on a comparison of results between companies that concluded an M\&A and those that did not. The aim of previous research was to find out whether the former perform better, and which indicators reflect the improvement.

Our research is based on the analysis of the results of combined companies, and we sought to find out whether there are any differences in the development of their indicators and what might be the cause. This led us to examine the results of the companies several years before and after the merger. We then divided the companies into two groups based on their postmerger performance: one group consisted of successfully merged companies, the other group consisted of companies that failed to achieve any improvement after the merger. We made a comparison of the two groups of companies in an effort to find out the reasons for success and to identify indicators that can serve as predictors of future success at the time when a new M\&A is being prepared.

We have been engaged in research into M\&A effectiveness for several years. In our first study, we evaluated the M\&A effectiveness three years after the merger. In our current research, we prolonged the period of time in which we analyse the same transactions. We chose this approach on the assumption that an M\&A is a financially demanding transaction whose effectiveness might only be apparent after a fairly long interval. A prolonged time period can help us observe changes that occur only later after the deal.

\section{Research methodology}

\subsection{Division of mergers into successful and unsuccessful ones}

Mergers were divided into successful and unsuccessful ones (i.e. creating vs. not creating synergies) based on changes in sales and net income. Selection criteria for the division of mergers were based on our knowledge of value drivers, i.e. the year-over-year sales growth 
rate and operating profit margin, which are among the seven key value drivers that contribute to the growth of the company's value.

The change in sales was calculated on the basis of the real $\left(\mathrm{S}_{\mathrm{R}}\right)$ and theoretical $\left(\mathrm{S}_{\mathrm{T}}\right)$ values of sales as $\Delta \mathrm{S}=\mathrm{S}_{\mathrm{R}}-\mathrm{S}_{\mathrm{T}}$, i.e., the increase in sales was not calculated on the basis of a comparison of pre-merger and post-merger sales. We chose a different approach, namely a comparison of the development of real and theoretical (potential) sales. We first calculated the potential sales that the companies would have achieved with no change in their status, i.e. if they had continued to operate as stand-alone companies. The value of the average growth rate of sales in the past was used in the calculation. The theoretical value of sales was then determined as the sum of the expected sales of the merging companies as of the date of comparison, i.e. three and five years after the merger. Real sales are the sales of the combined company three and five years after the merger.

The change in net income was calculated in a similar manner.

\subsection{Financial indicators}

When comparing successful and unsuccessful mergers, we used financial indicators that had been used by other authors (see the overview in Introduction), and those identified in our previous research (see [13]) - see Table 1.

Table 1. Financial indicators examined

\begin{tabular}{|l|c|l|c|}
\hline \multicolumn{1}{|c|}{ Financial indicator } & Abbreviation & \multicolumn{1}{|c|}{ Financial indicator } & Abbreviation \\
\hline Assets Turnover & S/A & Inventory Turnover & S/InV \\
\hline Bank Loans/ Assets & BL/A & Labour Cost/ Sales & LC/S \\
\hline Cash/ Assets & Cash/A & Added value/ Labour Cost & AV/LC \\
\hline Cash Flow/ Assets & CF/A & Leverage Ratio & LR \\
\hline Cash Flow/ Interest & $\mathrm{CF} / \mathrm{I}$ & $\begin{array}{l}\text { Liabilities/ Production } \\
\text { Consumption }\end{array}$ & $\mathrm{L} / \mathrm{PC}$ \\
\hline Cash Flow/ Sales & $\mathrm{CF} / \mathrm{S}$ & Receivables/Sales & $\mathrm{R} / \mathrm{S}$ \\
\hline $\begin{array}{l}\text { Production Consumption/ } \\
\text { Sales }\end{array}$ & $\mathrm{PC} / \mathrm{S}$ & $\begin{array}{l}\text { Net Working Capital/ } \\
\text { Assets }\end{array}$ & $\mathrm{NWC/A}$ \\
\hline $\begin{array}{l}\text { Material Consumption/ } \\
\text { Sales }\end{array}$ & $\mathrm{MC} / \mathrm{S}$ & Net working capital/ Sales & NWC/S \\
\hline Depreciation/ Sales & $\mathrm{D} / \mathrm{S}$ & Return on Assets & $\mathrm{ROA}$ \\
\hline Fixed Assets/ Assets & $\mathrm{FA} / \mathrm{A}$ & Return on Equity & $\mathrm{ROE}$ \\
\hline
\end{tabular}

Most of the indicators selected measure mainly operational efficiency, because our previous research showed that combined companies achieve operational synergy rather than financial synergy [13]. Also included are indebtedness indicators. By analysing them, we intend to monitor changes in corporate indebtedness and the methods of financing M\&As. We also included indicators constructed on the basis of cash flow in the research. The reason is that the most widespread method of determining the value of companies is the discounted cash flow method, i.e. cash flow is considered an indicator that directly affects a company's value.

\subsection{Test of indicator significance}

Both groups of mergers (successful and unsuccessful) were analysed to see if there exist indicators take a different value in the groups of successful and unsuccessful mergers. We intended to find whether there are indicators that can signal the potential for a merger success. 
To analyse the indicators, we used the nonparametric Mann-Whitney $U$ test, which is an alternative to the t-test and is used when the normal data distribution assumption is not met [14]. Another condition for using the Mann-Whitney U test is that the examined groups are independent, i.e. there is no relationship between the values in individual groups.

The calculation of the test is based on the serial numbers of individual variation rows. According Bedanova [15], it is necessary first to create the so-called "composite selection", i.e. all transactions should be arranged in a single ascending order regardless of their original group. In the second step, the individual values in the composite selection are assigned with the ranking. The lowest value is assigned with the serial number one; the highest value is assigned with the highest serial number (in our case 49). This coding will contribute to the elimination of extreme values which negatively affect the research results. If multiple values coincide, they are assigned with an average ranking. The selection arranged in this manner is then used for calculating the sum of the rankings within each examined group (labelled RU and RN). Consequently, it is necessary to calculate the tested statistics according to the following relationships:

$$
\begin{aligned}
& U_{U}=n_{U} * n_{N}+\frac{n_{U^{*}\left(n_{U}+1\right)}}{2}-R_{U} \\
& U_{N}=n_{U} * n_{N}+\frac{n_{N^{*}\left(n_{N}+1\right)}}{2}-R_{N}
\end{aligned}
$$

Where:

$\mathrm{U}_{\mathrm{U}}=$ tested statistics of successful transactions

$\mathrm{U}_{\mathrm{N}}=$ tested statistics of unsuccessful transactions

$\mathrm{n}_{\mathrm{U}}=$ number of transactions included in the group of successful transactions

$\mathrm{n}_{\mathrm{N}}=$ number of transactions included in the group of unsuccessful transactions

$\mathrm{R}_{\mathrm{U}}=$ sum of rankings related to the values of successful transactions

$\mathrm{R}_{\mathrm{N}}=$ sum of rankings related to the values of unsuccessful transactions

The smaller of the test statistics, i.e. $U=\min \left(U_{U}, U N\right)$ is subsequently used as a test criterion assessed with the critical value of the Mann-Whitney test [15].

\subsection{Data}

In our research, we examined data from private companies in the Czech Republic. The research sample selection was based on the following criteria:

- the merger was carried out by companies domiciled in the Czech Republic between 2004 and 2011;

- it was the company's only merger over a period of 9 years (three years before the merger, the year of the merger and five years after the merger).

- the financial statements of the acquirer and of the target company are publicly available (published on the portal www.justice.cz).

Based on the above criteria, we selected 49 mergers involving 100 companies from the mechanical engineering sector (CZ-NACE 25 and 28). Twenty-five were horizontal mergers, i.e. mergers between firms operating in the same line of business, and 24 were vertical mergers, i.e. mergers between suppliers and customers.

\section{Results}

Our analysis showed differences in results when the effect of the merger was assessed three and five years after the merger. The division of mergers into successful and unsuccessful 
ones on the basis of a change in sales and profits 3 and 5 years post-merger is shown in Table 2 .

Table 2. Numbers of successful and unsuccessful mergers 3 and 5 years following merger

\begin{tabular}{|l|c|c|}
\hline \multirow{2}{*}{ Number of mergers } & \multicolumn{2}{|c|}{ number of years after merger } \\
\cline { 2 - 3 } & 3 & 5 \\
\hline successful & 23 & 25 \\
\hline unsuccessful & 26 & 24 \\
\hline
\end{tabular}

The first group was made up of companies that achieved synergy after the merger, i.e. recorded an increase in sales or net income. The total number of successful and unsuccessful transactions varied depending on the number of years after the merger. A detailed analysis shows that four transactions were reclassified: three that were considered unsuccessful three years after the merger were reclassified as successful five years following the merger. There were two reasons for the reclassification: two mergers achieved an improvement in their costeffectiveness at the end of the considered period with a consequent increase in net income. The second reason was sales growth. On the other hand, one merger is reclassified as unsuccessful due to a drop in sales by a third (which was subsequently reflected in a decline in net income).

The transactions thus divided were examined on the basis of the development of financial ratios over the entire period under consideration, i.e. over five years. Selected results, specifically obviously different average values of indicators, are shown in Table 3 . The values are given for the year before the merger (period -1) and for years 3 to 5 of the postmerger period (period 3-5). Using the data from selected years, we present the development of indicators in individual periods.

Table 3. Development of financial indicators

\begin{tabular}{|l|c|c|c|c|c|c|c|c|}
\hline & \multicolumn{4}{|c|}{ Successful mergers } & \multicolumn{4}{c|}{ Unsuccessful mergers } \\
\hline Period & -1 & 3 & 4 & 5 & -1 & 3 & 4 & 5 \\
\hline D/S & 0.0511 & 0.0288 & 0.0269 & 0.0282 & 0.0362 & 0.0343 & 0.0364 & 0.0389 \\
\hline LC/S & 0.1159 & 0.1130 & 0.1093 & 0.1081 & 0.1115 & 0.1333 & 0.1329 & 0.1394 \\
\hline CF/A & 0.1224 & 0.1252 & 0.1399 & 0.1299 & 0.1194 & 0.0948 & 0.0747 & 0.0881 \\
\hline ROA & 0.0339 & 0.0972 & 0.1198 & 0.1079 & 0.0793 & 0.0535 & 0.0393 & 0.0513 \\
\hline LR & 0.4114 & 0.5064 & 0.5128 & 0.4775 & 0.4699 & 0.4649 & 0.4406 & 0.4922 \\
\hline S/Inv & 2.4857 & 2.7422 & 2.6567 & 2.8468 & 2.2353 & 2.5276 & 2.1454 & 2.3167 \\
\hline
\end{tabular}

During the period under consideration, the depreciation-to-sales value in the group of successful mergers decreased by almost $45 \%$ compared with the pre-merger situation. The high value before the merger indicates that the companies had a relative excess of fixed assets, which were apparently disposed of after the merger. This resulted in a reduction of the companies' fixed operating costs. No such effect was detected in unsuccessful mergers, with the depreciation to sales indicator remaining at approximately the same value. It needs to be added that these values in the companies were different even before the merger.

Both groups of companies had an almost identical labour cost to sales ratio before the merger. This is due to the fact that only companies from the same sector were included in the research. After the merger, however, their development followed a different course as the gap between the companies involved in a successful merger and those whose merger was not successful began to widen. In the last monitored year (year 5 after the merger) the difference between the groups of companies was 3.13 percentage points. 
Another indicator that deserves attention is the cash flow to assets ratio. In successful mergers, it remained approximately the same throughout the period under consideration. In unsuccessful transactions, its value dropped, i.e. the ability to generate cash flow from available assets decreased.

All three factors mentioned were subsequently projected into the ROA indicator, which increased in successful M\&As (3.18 times compared with the pre-merger situation) but decreased in unsuccessful M\&As (by about 35\%).

The differences between indicators identified by a simple assessment were further tested for statistical significance using the Mann-Whitney U-test. The results of the significance test are shown in Table 4.

Table 4. Mann-Whitney U test

\begin{tabular}{|l|c|c|c|c|c|c|c|c|c|}
\hline & -3 & -2 & -1 & 0 & 1 & 2 & 3 & 4 & 5 \\
\hline PC/S & 0.1650 & 0.1226 & 0.7634 & 0.1274 & 0.2401 & 0.4316 & 0.4316 & 0.0930 & $\mathbf{0 . 0 3 5 1}$ \\
\hline MC/S & 0.5029 & 0.2560 & 0.4665 & 0.1203 & 0.1867 & 0.2212 & 0.2519 & $\mathbf{0 . 0 2 6 9}$ & $\mathbf{0 . 0 1 1 9}$ \\
\hline NWC/S & 0.2899 & 0.2176 & 0.3563 & 0.3463 & 0.0893 & 0.1535 & 0.1092 & 0.4906 & 0.4316 \\
\hline NWC/A & 0.2104 & 0.5280 & 0.7634 & 0.3666 & 0.6763 & 0.9304 & 0.8233 & 0.9613 & 0.2479 \\
\hline FA/A & 0.8996 & 0.5029 & 0.5537 & 0.5280 & 0.7049 & 0.5933 & 0.3929 & 0.5472 & 0.5216 \\
\hline S/A & 0.3463 & 0.5668 & 0.9923 & 0.9768 & 0.2642 & 0.1966 & 0.1135 & 0.0510 & $\mathbf{0 . 0 1 4 8}$ \\
\hline S/Inv & 0.6622 & 0.8007 & 0.5733 & 0.4489 & 0.2104 & 0.3929 & 0.1932 & 0.0665 & $\mathbf{0 . 0 2 4 9}$ \\
\hline LC/S & 0.9304 & 0.9923 & 0.9149 & 0.7487 & 0.7049 & 0.4547 & 0.2000 & 0.2944 & 0.1203 \\
\hline AV/LC & 0.0609 & $\mathbf{0 . 0 0 9 0}$ & $\mathbf{0 . 0 4 0 5}$ & 0.2176 & 0.7194 & 0.6343 & 0.0740 & 0.4037 & 0.0772 \\
\hline L/PC & 0.4203 & 0.1535 & 0.6068 & 0.9923 & 0.3769 & 0.1274 & 0.4092 & $\mathbf{0 . 0 2 0 3}$ & $\mathbf{0 . 0 0 1 0}$ \\
\hline R/S & 0.7487 & 0.3173 & 0.9304 & 0.4547 & 0.5029 & 0.2642 & 0.4785 & 0.1274 & $\mathbf{0 . 0 0 7 6}$ \\
\hline D/S & 0.3875 & 0.3769 & 0.8233 & 0.6482 & 0.4316 & 0.3875 & 0.0694 & $\mathbf{0 . 0 4 5 5}$ & 0.0680 \\
\hline ROA & 0.1008 & $\mathbf{0 . 0 0 8 5}$ & 0.2176 & 0.2324 & 0.5280 & 0.2479 & 0.0857 & $\mathbf{0 . 0 0 8 5}$ & $\mathbf{0 . 0 0 9 5}$ \\
\hline ROE & 0.1592 & $\mathbf{0 . 0 4 8 7}$ & 0.4203 & 0.2176 & 0.8233 & 0.9458 & 0.0789 & $\mathbf{0 . 0 0 6 4}$ & $\mathbf{0 . 0 1 2 6}$ \\
\hline Cash/A & $\mathbf{0 . 0 1 7 4}$ & 0.1535 & 0.1480 & 0.1899 & 0.3080 & 0.5029 & 0.7783 & 0.8384 & 0.6906 \\
\hline LR & 0.9923 & 0.8082 & 0.4906 & 0.5933 & 0.7783 & 0.5408 & 0.6906 & 0.5668 & 0.3563 \\
\hline BL/A & 0.4203 & 0.7194 & 0.9923 & 0.8842 & 0.8233 & 0.8082 & 0.3666 & 0.7194 & 0.4547 \\
\hline CF/A & 0.0558 & $\mathbf{0 . 0 2 0 3}$ & 0.4316 & 0.3268 & 0.3875 & 0.2479 & 0.1535 & $\mathbf{0 . 0 1 4 8}$ & $\mathbf{0 . 0 0 7 6}$ \\
\hline CF/I & $\mathbf{0 . 0 0 8 3}$ & $\mathbf{0 . 0 2 2 5}$ & $\mathbf{0 . 0 4 8 7}$ & 0.2249 & 0.7487 & 0.4431 & 0.6906 & 0.1710 & 0.2899 \\
\hline CF/S & $\mathbf{0 . 0 4 8 7}$ & $\mathbf{0 . 0 0 3 9}$ & 0.5154 & 0.2812 & 0.9923 & 0.7487 & 0.5029 & 0.4316 & 0.2324 \\
\hline
\end{tabular}

The test results unambiguously show that the tested indicators take different values in the 4 th and 5th year after the merger in the group of successful and unsuccessful mergers. In the original research carried out on data three years after the merger, a significant difference in the labour cost to sales $(\mathrm{LC} / \mathrm{S})$ indicator was identified as early as one year after the merger but that difference is statistically insignificant after the extension of the time horizon. A similar situation occurred with the depreciation to sales $(D / S)$ indicator. In the original research (three years after the merger), a statistically significant difference was identified already in the year of the merger. A statistically significant difference in the value of that indicator is now only in the fourth year of the post-M\&A period.

As a result of the prolonged testing period, more financial indicators were identified that had different values even before the merger took place. In the original research (three years post-merger), such indicators were only ROA, ROE and CF/A. The newly identified indicators included added value to labour cost (AV/LC), cash to assets (Cash/A), cash flow to interest $(\mathrm{CF} / \mathrm{I})$ and cash flow to sales $(\mathrm{CF} / \mathrm{S})$. All of these indicators can be considered predictors that can signal a success, or a failure of an intended merger should it take place. 
Furthermore, we identified indicators that were statistically significantly different in the group of successful and in the group of unsuccessful mergers in the fourth and fifth postmerger year. They are production consumption to sales (PC / S), material consumption to sales $(\mathrm{MC} / \mathrm{S})$, assets turnover $(\mathrm{S} / \mathrm{A})$, inventory turnover $(\mathrm{S} / \mathrm{Inv})$, liabilities to production consumption $(\mathrm{L} / \mathrm{PC})$, receivables to sales $(\mathrm{R} / \mathrm{S})$ and depreciation to sales $(\mathrm{D} / \mathrm{S})$ indicators, i.e. indicators that define operating performance. Successful combined companies clearly make better use of their assets to generate sales, have lower levels of both receivables and payables, as well as a lower operating costs to sales ratio. The merger effect was particularly pronounced in the fourth and fifth years of the post-M\&A period.

\section{Discussion}

A number of significant changes were observed when mergers were monitored over a prolonged period of time. The first thing noted was the change in classification of several mergers. Four mergers were reclassified, which represents approximately $8 \%$ of the sample examined. Of these, three mergers were transferred from the group of unsuccessful to the group of successful mergers. All three mergers reported increased profitability. The situation got worse in one merger only. The company in question is large with assets in excess of 500 million CZK and revenues higher than 1 billion CZK throughout the period under consideration. The company's core activity is in the foundry business and was the result of a vertical merger. Because the merger took place in 2004, it might be argued that the reclassification into the group of unsuccessful mergers was the consequence of the economic crisis that hit the Czech Republic in 2008-2012. This factor certainly played a role in the company's results, but we should point out that the drop in the company's sales was bigger than the average drop in the industry.

The new classification of mergers into groups also brought about changes in the average indicator values. Changes, however, were also due to the prolonged study period. In successful mergers, an improvement in the indicators examined can be observed in the fourth and fifth year after the M\&A transaction. Companies in this group achieved a drop in the labour cost to sales indicator, which may have been due to higher labour productivity in those companies. Improvement was also noted in the return on assets (probably thanks to a better assets utilization) and cash flow to assets indicators, i.e. the company's ability to generate cash flow is improving. Companies in the group of unsuccessful mergers reported no significant changes during the prolonged time period, i.e. the values of indicators remained largely unchanged.

On the basis of our results, we can state that there is a difference in indicators characterizing the utilization of assets between the group of successful and the group of unsuccessful mergers. This is evident from the development of the assets turnover and inventory turnover indicators. The difference in average values of the two indicators (between the groups of successful and unsuccessful mergers) is in the fifth year after the merger. This means that disposable assets were made a better use of, which was reflected in an increase in return on invested capital. This phenomenon is very desirable, because its heralds a potential for profitability growth. In this context, we consider it appropriate to mention that better use of assets after the merger was also demonstrated in [4], and Golubov and Xiong [10] in the case of M\&As of private companies.

Other indicators in which statistically significant differences were identified also point to higher efficiency of operating activities. They are the production consumption to sales, material consumption to sales and depreciation to sales indicators. The comprehensive manifestation of positive changes in assets utilization and a decrease in costs is the growth of profitability (ROA, ROE). We noted that this positive development was not identified in 
previous research (three years after the merger). The indicators mentioned did not reach significant differences until the fourth and fifth years after the merger.

However, profitability ratios were already significantly higher two years before the merger in the group of companies that eventually completed a successful merger. It can be deduced from this fact that mergers probably required additional costs that were reflected in a temporary drop in corporate profitability. Another explanation for the temporary decrease in efficiency may be the high demands of merger implementation which detract the company management's attention from its focus to such an extent that managers do not have time to pay enough attention to managing sales and production processes, and the overall company's performance suffers. These conclusions also follow from the values of operational performance indicators, which deteriorate in the first years after the merger but pick up later.

The logical consequence of the earnings growth (ROA) is an increase in the cash flow that the company generates from its activities. In our research, this fact was reflected in the value of the cash flow to assets indicator, which also takes a significantly different value in the group of successful mergers and in the group of unsuccessful mergers. We also wish to add that the differences in the indicators constructed on the basis of cash flow between the companies that completed a merger and the companies that were not involved in any merger were also reported in [5].

\section{Conclusion}

In this paper, we present the results from ongoing research into the effectiveness of mergers. In this stage of research, we examined the influence of the length of monitoring on the evaluation of merger effectiveness, i.e. we examined whether the effect of mergers can manifest itself after a prolonged period of time. In our previous study, we evaluated the effectiveness of mergers three years after the transaction. In this study, mergers were evaluated five years after completion.

The results of our research unambiguously confirmed that extending the time horizon (number of years after the merger) increases the number of successful mergers. And more importantly, new indicators were identified that take different values in companies involved in a successful merger and those whose merger was not a success. By extending the time horizon, one new indicator was identified that is statistically significantly different in the two groups even before the merger takes place, namely the added value to labour cost ratio, which was different for two years before the merger (i.e. in the -2 to -1 period). The rest of the indicators remained the same as in our previous study. These indicators can be used to construct models for predicting merger success, i.e. to estimate in advance the likelihood of success or failure of a planned merger.

Acknowledgement: The authors are grateful to the IGA of BUT No. FP-S-20-6466 "Prediction models in finance: Specifics of SMEs" for financial support provided to conduct this research.

\section{References}

1. Martynova, M., Renneboog, L. (2008). A century of corporate takeovers: What have we learned and where do we stand? Journal of Banking, 32(10), 2148-2177.

2. Gugler, K., Mueller, D. C., Yurtoglu, B. B., Zulehner, C. (2003). The effects of mergers: an international comparison. International Journal of Industrial Organization, 21(5), 625-653. 
3. Cartwright, S., Schoenberg, R. (2006). Thirty Years of Mergers and Acquisitions Research: Recent Advances and Future Opportunities. British Journal of Management, 17(S1), S1-S5.

4. Healy, P. M., Palepu, K. G., Ruback, R. S. (1992). Does corporate performance improve after mergers? Journal of Financial Economics, 31(2), 135-175.

5. Sorensen, D. E. (2000). Characteristics of merging firms. Journal of Economics and Business, 52(5), 423-433.

6. Shim, J. (2011). Mergers \& Acquisitions, Diversification and Performance in the U.S. Property-Liability Insurance Industry. Journal of Financial Services Research, 39(3), 119-144.

7. Koller, T., Goedhart, M. H., Wessels, D. (2015). Valuation: measuring and managing the value of companies (6th edition). Wiley.

8. Huyghebaert, N., Luypaert, M. (2010). Antecedents of growth through mergers and acquisitions: Empirical results from Belgium. Journal of Business Research, 63(4), 392403.

9. Sedlacek, J., Valouch, P., Konecny, A. (2013). Synergic motives and economic success of mergers of Czech companies. Acta Universitatis Agriculturae et Silviculturae Mendelianae Brunensis, 61(7), 2721-2727.

10. Golubov, A., Xiong, N. (2020). Post-acquisition performance of private acquirers. Journal of Corporate Finance, 60, 101545.

11. Cui, H., Leung, S. C. M. (2020). The long-run performance of acquiring firms in mergers and acquisitions: Does managerial ability matter? Journal of Contemporary Accounting \& Economics, 16(1), 18.

12. Wu, C., Yu, X., Zheng, Y. (2020). The spillover effect of financial information in mergers and acquisitions. The British Accounting Review, 52(4), 19.

13. Reznakova, M., Peta, J. (2016). Efficiency of Mergers of Mechanical Engineering Companies in the Czech Republic. Review of Economic Perspectives, 16(4), 361-374.

14. Kasuya, E. (2001). Mann-Whitney U test when variances are unequal. Animal Behaviour, 61(6), 1247-1249.

15. Bedanova, I. (2011). Nemarametricke testy. Biostatistika. Retrieved May 18, 2016. http://cit.vfu.cz/statpotr/POTR/Teorie/Predn4/MannWhit.htm. 